\title{
The Acoustical Properties of the Polyurethane Concrete Made of Oyster Shell Waste Comparing Other Concretes as Architectural Design Components
}

\author{
Erni Setyowati ${ }^{1, *}$, Gagoek Hardiman ${ }^{1}$, and Purwanto $^{2}$ \\ ${ }^{1}$ Department of Architecture, Faculty of Engineering, Diponegoro University, Semarang - Indonesia \\ ${ }^{2}$ Department of Civil Engineering, Faculty of Engineering, Diponegoro Univers ity, Semarang - Indonesia
}

\begin{abstract}
This research aims to determine the acoustical properties of concrete material made of polyurethane and oyster shell waste as both fine aggregate and coarse aggregate comparing to other concrete mortar. Architecture needs aesthetics materials, so the innovation in architectural material should be driven through the efforts of research on materials for building designs. The DOE methods was used by mixing cement, oyster shell, sands, and polyurethane by composition of $160 \mathrm{ml}: 40 \mathrm{ml}: 100 \mathrm{ml}: 120 \mathrm{ml}$ respectively. Refer to the results of previous research, then cement consumption is reduced up to $20 \%$ to keep the concept of green material. This study compared three different compositions of mortars, namely portland cement concrete with gravel (PCG), polyurethane concrete of oyster shell (PCO) and concrete with plastics aggregate (PCP). The methods of acoustical tests were conducted refer to the ASTM E413-04 standard. The research results showed that polyurethane concrete with oyster shell waste aggregate has absorption coefficient 0.52 and STL $63 \mathrm{~dB}$ and has a more beautiful appearance when it was pressed into moulding. It can be concluded that polyurethane concrete with oyster shell aggregate (PCO) is well implemented in architectural acoustics-components.
\end{abstract}

\section{Introduction}

Innovation in concrete materials has been developed significantly. The use of materials and filler additive for designation are examined. One of the efforts to reduce cement and lighten the concrete material is the use of a foam additive such as polyurethane [1], [2] and polystyrene [3]. The use of foam additive in concrete material is also beneficial for the invention of the acoustic-based cement composite material. While other studies used polyesther in concrete for the purpose of increasing harshness on building materials[4], [5].

This research is focused on the acoustic performance of polyurethane concrete material made of oyster shell waste compared to other concrete materials.

\section{Theoretical Review}

The theoretical review will discuss the oyster shell concrete and polyurethane concrete as basic material in this study. Previous research stated that the oyster shell concrete made of anadara granosa lynn species has the strongest compressive strength comparing to the other shell concrete[6], [7]. This study focused on the use of the polyurethane in concrete to lighten it and improve the capability of acoustics.

\subsection{Oyster Shell Concrete}

Previous research has compared three different types of concrete material made of three species of shells. Three shell concrete specimens made of Anadara granosa Lynn, Perna viridis and Placuna placenta Lynn have tested both the ability of compressive strength as well as acoustic abilities. The result is that shell concrete of Anadara granosa Lynn has highest compressive strength up to $200 \mathrm{~kg} / \mathrm{cm}^{2}$ [6]. Meanwhile, shell concrete made of Perna viridis Lynn has the best acoustic capabilities, with $7.28 \mathrm{~dB}$ on it's Sound Transmission Loss [7].

Because this study observing the concrete material based on the previous research, then the selected species is Anadara granosa Lynn either as fine aggregate or coarse aggregate, due to it's performance either in compressive strength or acoustical performances. While for other selected materials are polymeric concrete (PCP) and normal concrete with gravel aggregates (PCG).

\subsection{Acoustical Performance of Shell Material}

Research on the shell concrete material for noisy urban region has been already conducted. The result is that material of oyster shell with porous additive substances can be used to absorb sound in housing near the airports[8]. Oyster shell material without additive substance will not have a good acoustic performance, 
due to the low absorption coefficient between $0.03-$ 0.04[7]. Even, the fly ash mixed with oyster shell will reduce pores and reduce the ability of sound absorber [9].

\subsection{Previous Research of Concrete}

The normal concrete with coarse aggregate (PCG) and Polymeric Concrete (PCP) have been already examined in the previous researches. The method used was a mix design with DOE Methods. On polymeric concrete (PCP), the aggregate of polymeric waste used to replace gravel aggregate and a part of cement was substituted by baggase ash [10], [11]. Meanwhile, the normal concrete is portland cement concrete with gravel (PCG). PCG has a normal compressive strength that is equivalent $>$ Q250. The harshness of normal concrete tends to have capabilities as a reflector.

The normal concrete (PCG) and polymeric concrete (PCP) have the composition ratio of cement (plus baggase ash), sand and gravel or polymeric waste as 2,$600 ; 2,220 ; 0,635$ respectively, while the Polyurethane concrete with shell aggregate has composition of cement, oyster shell, sand and polyurethane as 1,600; 0,$400 ; 1,000 ; 1,200$ respectively. The moulding of material used are cubical mouldings as seen in fig. 1. The figure below shows the mixture of materials.

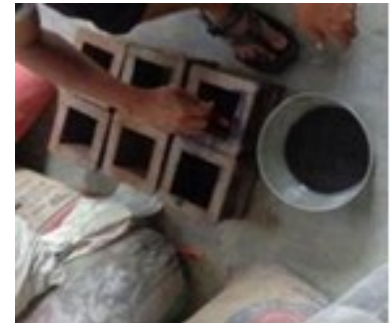

(a)

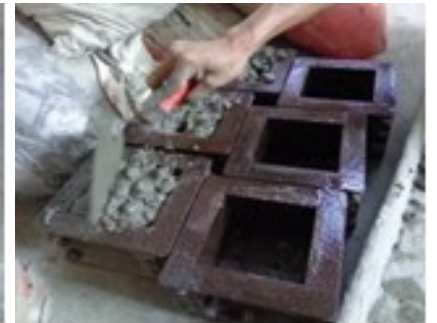

(b)
Fig. 1. (a) cubical moulding (b) mix design process of materials

\section{Research Methods}

Acoustic characteristics in this study consist of absorption coefficient $(\alpha)$ and Sound Transmission Loss (STL).

\subsection{Absorption Coefficient}

The impedance tube with $1 / 3$ octave frequency filter was used in the sound absorption test. The data were connected into Personal Computer (PC) by software refer to ASTM E413-04[12]. The sound absorption coefficient $\left(\alpha_{0}\right)$ was calculated by measuring sound pressure that come on a surface of material and was reflected by it. A good absorber must have an absorption coefficient at least 0.2 [7], [13-15].

$$
\alpha_{0}=\frac{4}{n+\left(\frac{1}{n}\right)+2}
$$

Where $\alpha_{0}$ is sound absorption coefficient and $n$ is standing wave ratio. The standing wave ratio (n) is measured by substituting resistance with attenuation, determining the ratio of the standing waves from the difference of sound pressure (L) $\mathrm{dB}$ using equation as follows:

$$
n=10^{\left(\frac{L}{20}\right)}
$$

With $n$ is a standing wave ratio and $L$ is the difference of sound pressure in deci Bell. In the process of the absorption coefficient test $(\alpha)$. The impedance tube was equipped by microphones to transmit sound at low to high frequencies. The Frequency scale that was used in acoustics laboratory is between $200-6000 \mathrm{~Hz}$.

\subsection{Sound Transmission Loss (STL)}

The Sound Transmission Loss (STL) Test used impedance tube equipped with 4 microphones (see fig.2) that have sensitivity to high frequency sound.

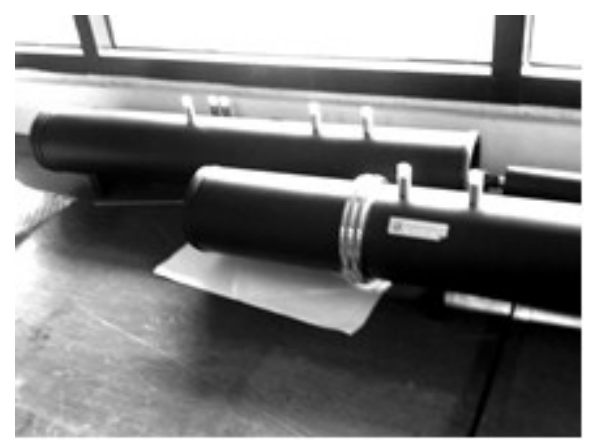

Fig.2. The Impedance Tube with microphones

Sound Transmission Loss/STL of a partition is defined as the ratio of logarithmic between the transmitted sound powers (Wt) and the sound power of partition material which comes to the surface (Wi). In general it can be formulated as:

$$
\begin{gathered}
T L=10 \log \frac{W_{t}}{W_{i}} \\
T L=10 \log \frac{1}{r}
\end{gathered}
$$

With $r$ is the sound transmission coefficient of such material, i.e. the ratio between the transmitted sound power through partition of material against the sound felt through the material's surface. The STC value is a parameter to know how the material can reduce sound energy[7]. The STC is determined based on the raw 
quality ASTM E 413 issued by the American Society for Testing and Materials[12].

\section{Results and Discussion}

\subsection{Absorption Coefficient}

The absorption coefficient test results of materials, PCG, PCO and PCP are as follows:

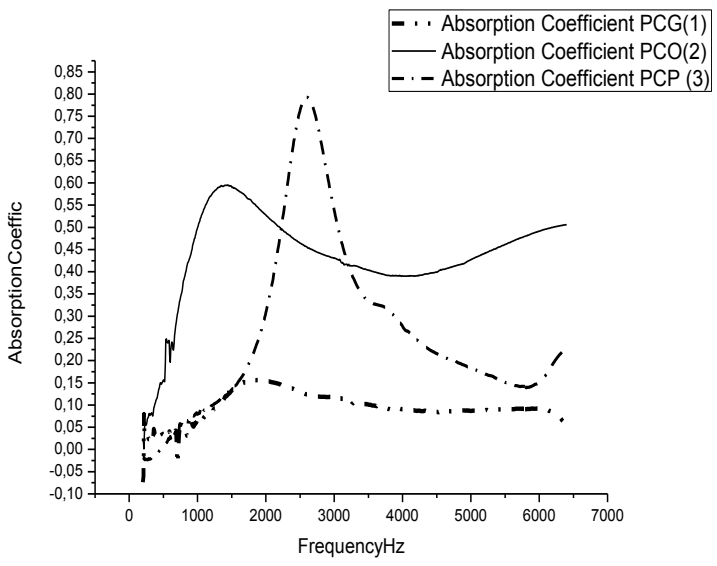

Fig. 3. Absorption Coefficient Graph of materials

As shown in the graph (see fig. 3), PCG and the PCP have characters on absorption coefficient of octave frequencies which are almost similar. PCG has a coefficient of absorption peaks in 0.155 at frequency $1968 \mathrm{~Hz}$, while the PCP has the highest coefficient of 0.793 on frequency $2,6 \mathrm{k}$ (see Table 1 ).

Table 1. Absorption Coefficient on octave band frekuensi

\begin{tabular}{|c|c|c|c|}
\hline $\begin{array}{c}\text { Frequency } \\
(\mathbf{H z})\end{array}$ & $\boldsymbol{\alpha}$ PCG & $\boldsymbol{\alpha}$ PCO & $\boldsymbol{\alpha}$ PCP \\
\hline 1000 & 0,0626 & 0,4989 & 0,0783 \\
\hline 1432 & 0,1211 & 0,5951 & 0,1266 \\
\hline 1968 & 0,1550 & 0,5315 & 0,2892 \\
\hline 2600 & 0,1238 & 0,4559 & 0,7929 \\
\hline 3000 & 0,1193 & 0,4305 & 0,5381 \\
\hline 4000 & 0,0912 & 0,3906 & 0,2770 \\
\hline 5000 & 0,0867 & 0,4271 & 0,1813 \\
\hline
\end{tabular}

Unlike the PCG and PCP, hence the absorption coefficient ranges of PCO is better, because the value of the coefficient is at a wider broadband frequency. Maximal absorption coefficients that can be achieved is 0.59508 in $1432 \mathrm{~Hz}$, but it is able to absorb sounds at lower frequencies than the other materials. The variations in the ability of absorbency at low to highfrequency sound are required in building materials, especially for the concert hall building design.

The polyurethane concrete material with shell aggregates (PCO) has a pretty good absorption coefficient because it has a capability to absorb sound energy in a wide broadband of octave frequency. But, in the future, this material need to be improved on acoustical performance by modification of resonator efforts as several researches conducted. Some modification efforts to improve absorption coefficient of resonators for examples with the use of flexible panels [16], coupled- Helmholtz resonator[17], [18], recycling material from industry[19], [20], sustainable absorber from biomass[21].

\subsection{Sound Transmission Loss (STL)}

Unlike normal concrete, polyurethane concrete with oyster shell (PCO) and polymeric concrete (PCP) have STL characters which are almost the same. Both materials have range of STL between 54-56 dB starting from around $2000 \mathrm{~Hz}$. At the frequency of $<500 \mathrm{~Hz}, \mathrm{PCP}$ has range of STL lower than $\mathrm{PCO}$ is, due to the polyurethane compound in PCO that absorbs and reduces sound energy more than polymeric concrete (PCP).

Sound Transmission Loss test results of all materials are as follows:

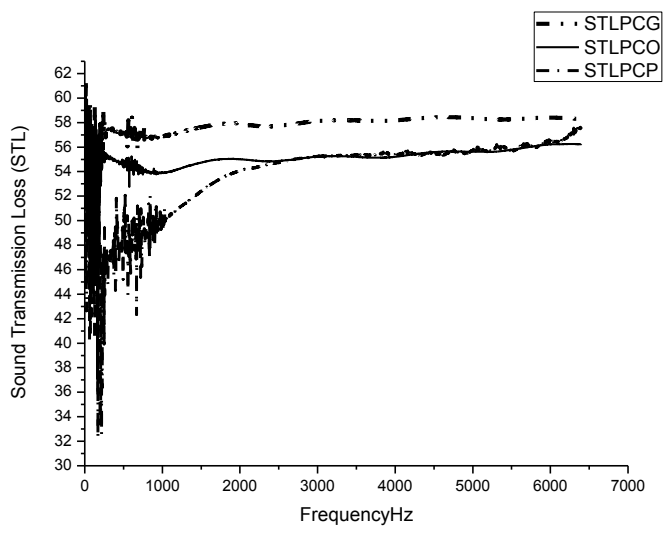

Fig. 4. Sound Transmission Loss (STL) of PCG, PCO and $\mathrm{PCP}$

The graph shows that the normal concrete (PCG) with aggregate gravel has the highest STL highest among other materials. The value of the STL of PCG ranged between 57-58 dB (see fig.4 and table 2).

The role of polyurethane here is as sound traps, so that the sound of falling on the surface are not forwarded to penetrate the material. The increased efforts of the STL 
has been done by a number of researchers, such as by adding material on acoustic resonator system[22].

Table 2. Absorption Coefficient in octave band frequencies

\begin{tabular}{|c|c|c|c|}
\hline $\begin{array}{c}\text { Frequency } \\
(\mathbf{H z})\end{array}$ & $\begin{array}{c}\text { STL PCG } \\
(\mathbf{d B})\end{array}$ & $\begin{array}{c}\text { STL PCO } \\
(\mathbf{d B})\end{array}$ & $\begin{array}{c}\text { STL PCP } \\
(\mathbf{d B})\end{array}$ \\
\hline 1000 & 56,9132 & 53,9376 & 49,456 \\
\hline 2000 & 57,8971 & 55,0005 & 54,0774 \\
\hline 2400 & 57,6903 & 54,8373 & 54,6301 \\
\hline 3000 & 58,1237 & 55,2227 & 55,2424 \\
\hline 4000 & 58,1805 & 55,2048 & 55,3544 \\
\hline 5000 & 58,364 & 55,6168 & 55,7178 \\
\hline
\end{tabular}

\subsection{The Use of Polyurethane Concrete in Architectural Design}

The use of Polyurethane concrete made of oyster shell waste in buildings have wide variations. Polyurethane concrete can be printed in color and texture on the surface. Here is the usage of polyurethane concrete on the application component of building materials (see fig. 5 and 6).

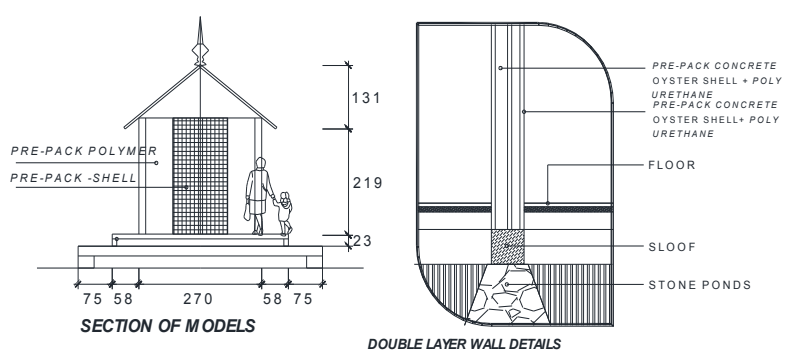

Fig. 5. Textured Polyurethane concrete in exterior double wall panel
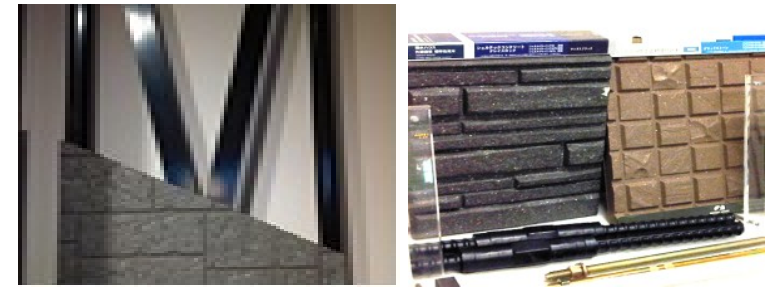

Fig. 6. Polyurethane concrete and colour innovation in Japanese industry.

Green architecture uses green concept materials, therefore discharging the innovation material that is capable of utilizing waste and reduces the use of cement is indispensable in the development of a sustainable green construction in architecture world.

\section{Conclusions}

The research was concluded a few things as follows:

1. Polyurethane concrete with oyster shell (PCO) are able to absorb sound in a wider frequency range than other materials.

2. Polyurethane concrete (PCO) can be used as absorber material on buildings as it can absorb sound energy at low to high frequency.

3. Normal concrete has the highest STL compared to other materials. While PCO has a better STL than PCP (polymeric concrete), because the content of polyurethane which is capable of trapping the sound.

4. Polyurethane concrete usage with shell aggregate (PCO) are excellent for building materials in the noisy urban region, because it was able to absorb the energy of the sound properly.

5. Green architecture is the architecture that is capable of utilizing waste based materials and is able to reduce the use of cement. By Polyurethane concrete material, the green construction can be realized because the material is lightweight and environmentally friendly.

This research is financed by the budget of the Research Grant from Ministry of Research, Technology and Higher Education, fiscal year 2017 with the scheme of Competency Grant and University of Diponegoro Grant Number: 276-47/UN7.5.1/PG/2017. The funders do not have any intervention on the data and the content of the manuscript. Authors thank all private sectors who have contributed in this research and gave the valuable opinion, advices and discourses.

\section{References}

1. I. Golpazir, A. Ghalandarzadeh, M. K. Jafari, and M. Mahdavi, Constr. Build. Mater., 118,104-115 (2016).

2. G. Sung, J. W. Kim, and J. H. Kim, J. Ind. Eng. Chem., 44, 99-104 (2016).

3. B. a. Erickson, Experimental study on the dynamic stress-strain behavior of expanded polystyrene Geofoam using cyclic triaxial tests, no. December 2011, p 45, (2011)

4. G. Martínez-Barrera, C. Menchaca-Campos, and O. Gencel, Constr. Build. Mater., 41, 204 208(2013).

5. I. J. Chiou, C. H. Chen, and Y. H. Li, Constr. Build. Mater., 64, 480-487 (2014).

6. E. Setyowati, G. Hardiman, and P. Purwanto, J. Teknologi , 78 (5), 203-207 (2016).

7. E. Setyowati and G. Hardiman, J. Eng. 
Technol., 3(3), 1-6 (2015)

8. E. Setyowati and H. Trilistyo, Procedia - Soc. Behav. Sci., 227, 294-299 (2016).

9. H. Wang, W. Kuo, C. Lin, and C. Po-yo, Constr. Build. Mater., 41, 532-537 (2013).

10. E. Setyowati and Purwanto, The Acoustical Characteristics of Polymer Mortar as a Green Concrete Material, in The 14th International Conference on Quality in Research, 2015, pp. 983-987.

11. E. Setyowati and Purwanto, The Polymer Brick as Nano-Technology based Material to Support Green Building Construction, in The 3rd Annual International Conference Proceedings on Architecture and Civil Engineering, 2015, pp. 224-228.

12. ASTM, ASTM E413-04 Classification for Rating Sound Insulation.

13. E. Setyowati, G. Hardiman, and E. E. Pandelaki, Structural, Acoustic and Aesthetic Performances of Double Wall Layer Made Of Oyster Shell And Polymer As Green Material In Green Construction," proceeding of ICENIS, December (2016).
14. E. Setyowati, A. Satyapratama, S. T. Atmadja, and G. Hardiman, J. Teknologi , 78(5), 289293 (2016).

15. E. Setyowati, G. Hardiman, and S. T. Atmaja, J. of Applied Mechanics and Material, 747, 221-225 (2015).

16. A. Sanada and N. Tanaka, Appl. Acoust., vol. 74(4), 509-516 (2013).

17. S. K. Tang, J.of Sound and Vibration, 279, 1085-1096 (2005).

18. D. Li and L. C. Ã, J. of Sound and Vibration, 305, 272-288, (2007).

19. F. Asdrubali, A. L. Pisello, F. D. Alessandro, F. Bianchi, M. Cornicchia, and C. Fabiani, Energy Procedia, 78, 321-326 (2015).

20. C. Buratti, E. Belloni, E. Lascaro, G. Anna, and P. Ricciardi, Energy Procedia, 101, 972-979 (2016).

21. D. J. Oldham, C. A. Egan, and R. D. Cookson, ble acoustic absorbers from the biomass, Appl. Acoust., 72(6), 350-363 (2011).

22. K. T. Chen, Y. H. Chen, K. Y. Lin, and C. C. Weng, Appl. Acoust,. 54(1), 71-82 (1998). 